\title{
7. Better journalism or better profits?: A key convergence issue in an age of concentrated ownership
}

\section{ABSTRACT}

Convergence has become an accepted form of journalism at media organisations around the world. These organisations are adopting a range of business models to find ways to pay for these innovations. The main drivers behind this radical change in media production are consumers' changing media habits, cheaper digital technology, and the disruptive forces that these two drivers generate. Technology also makes possible new forms of storytelling, which potentially allows journalists the chance to do better journalism through convergence. This article focuses on the key issue of whether editorial managers and journalists are embracing convergence to save money, or to do better journalism. It begins by defining convergence (while accepting the wide variety of definitions) and describing two main models of implementation. It then considers the factors that lead to easy introduction of convergence followed by the factors that hinder its introduction. Examples are provided of converged media around the world. This article ends with a warning about the dangers for democracy of misapplied convergence in an era of increasing concentration of ownership.

\section{STEPHEN QUINN}

Ball State University

S WITH many discussions about technology, media convergence -
also known as multiple-platform publishing - presents a fundamental
issue that must be resolved. As a business model, convergence is an 
ists should be able to produce more for the same or little more money, which means that media organisations are mainly concerned with productivity. Partnerships between television stations and newspapers provide major opportunities for cross promotion and marketing, where each medium recommends the next within the news cycle. From the journalist's perspective, convergence offers a chance to improve journalism by giving reporters the digital tools to tell stories in the most appropriate medium.

But this digital technology costs money, and people need time to learn how to use it. Convergence also needs organisational change. Newspaper consultant Andreas Pfeiffer believes that newspapers are moving inevitably in the direction of convergence. But he issued a word of caution: ' ... implementing this vision is far more challenging than it may seem from a safe distance. Setting up systems for multi-channel publishing is a complex and costly task. While defining a multi-channel publishing system is relatively easy on the conceptual level, making it work is far more challenging' (Pfeiffer 2000). The fundamental issue of implementation concerns the potential conflict between a business-oriented view of convergence (where cost saving is important) versus a journalist's perspective. For them convergence offers the potential to do better journalism. However, this will not save money; indeed it will cost money.

Given the spread of convergence around the world the tension between productivity and professional ideals will have profound implications for how journalism is practised in the future. And given the relationship between the media and democracy - where media traditionally provide the information which people use to make informed decisions - convergence also has implications for the future of the democratic process. If only one media company produces content for most media in a city such as Auckland, does this reduce the potential range of voices available to society? Would this mean that potentially the managers of that company could become the targets of powerful interest groups (such as advertisers and corporate lobbyists).

The Media Center at the American Press Institute in Reston, Virginia runs courses about convergence for both managers and journalists. Its director, Andrew Nachison, has identified these two main models and believes the business approach is winning in the United States: 'I think journalism is adjusting to and coping with market forces and business imperatives - [but] I don't think journalism is leading the charge' (2002). Almost two years later he 
refined his opinion slightly, suggesting that media managers had become so caught up in the economics of the industry that they did not recognise they were making decisions based on economic rather than journalistic principles. In this regard he makes the following observation: 'So we hear editors talking about brand extension and market penetration. They have absorbed the business jargon. The industry has co-opted business models and approaches. This is a more troubling trend, though in some respects it's nothing new' (2004).

Convergence is attractive to both media managers and practitioners because it satisfies consumer demands and lifestyles. Howard Tyner, a former editor of the Chicago Tribune who became senior vice-president of the Tribune Company, believes the business of journalism is about 'eyeballs' getting as many people as possible to look at your products. As he famously observed: 'We go where the audience is' (Tyner 2000). Convergence also protects an organisation's journalistic franchise in the sense that multipleplatform publishing - increasingly a preferred phrase for the more nebulous term 'convergence' - allows wider coverage of an area and permits crossmarketing of a single product. Organisations embrace multiple-platform publishing for a variety of reasons, just as they produce multiple forms of convergence. It would be safe to say that no two media groups produce the same form of convergence. Their reasons are connected with the perceptions and background of the people making the decisions. Managers see the financial benefits of having staff expand their expertise in many formats; meanwhile journalists in those organizations believe quality must be maintained and call for this to remain the paramount consideration in any change (Quinn 2002a: 59). It is important here to define what we mean by convergence.

\section{What is convergence?}

Variables such as legislation, technology, audiences, along with the society and culture into which convergence is introduced, influence the extent to which convergence is possible. These factors can also dictate the form that convergence takes. For these reasons, convergence has as many definitions as the people who define it. Keynote speakers at a November 2002 conference that Ifra1 organised regarding convergence found it difficult to agree on a definition. Some saw it as survival, as the only way for the media to continue (Horrocks 2002). Others saw it as an opportunity to repurpose existing content for multiple products and as a way to protect their place in the market (Aeria 
2002). Others perceived it as a means to deliver news and information to consumers in a new and different way, or to expand the franchise (Tyner 2002; Thelen 2002a). It would be safe to say that convergence has almost as many meanings as it has advocates.

Because the author is based in the United States, this article will tend to use examples from that country. In the United States the convergence process usually involves a daily newspaper partnering with a local television channel. It usually needs to be a win-win situation to be successful. Because dailies have the largest single group of reporters, they can bring depth to television's reporting. Television contributes its brand and wide reach to promote the newspaper. Ideally, each medium cross-promotes the other; highlighting the major stories that will appear on the medium that the audience can access soonest. Problems occur when one member of the partnership begins to feel that they are giving more to the relationship than the others. Larry Pryor, a professor at the Annenberg School for Communication at the University of Southern California, maintains that a shared definition is vital. In his view a new medium needs a common vocabulary: 'If we all have a different concept of what convergence means, we are making it difficult to progress.' Pryor was concerned that allowing the industry to define convergence would produce a simplistic definition with a limited scope: 'I'd prefer to see it defined by people who study the field and do the experimental work. This sounds self-serving, but that would be those of us at universities, although not necessarily in schools of journalism.' Pryor called for a joint effort among many disciplines such as engineering, cinema/TV, journalism, business, law and communications, supported by organisations such as the Poynter Institute and the Pew and Ford foundations, plus contributions from creative people in industry (Pryor 2004). This article will not discuss corporate convergence, where big companies merge because of the mutual benefits of amalgamation. Probably the best known of these was the $\$ 165$ billion AOL-Time Warner merger announced in January 2000. It was touted as convergence because analysts and executives saw advantages in combining Time Warner's content with AOL's networks.

Rich Gordon of Northwestern University identified at least five forms of convergence, in the context of the United States. Ownership convergence is his term to describe the large media companies which pushed for 'synergy' cross-promotion and content sharing between print and television owned by the same company. Gordon quotes the Tribune Company's president Jack 
Fuller: 'Owning television, radio and newspapers in a single market is a way to lower costs, increase efficiencies and provide higher quality news in times of economic duress' (2003: 64). Tactical convergence is Gordon's concept for the partnerships that have arisen in the US media. Tactical convergence does not require common ownership, just as ownership convergence does not imply collaboration on tactics. The most common model of tactical convergence was a partnership between a TV station and a newspaper, usually separately owned. It was a business arrangement: 'In most markets, the primary motivation for - and initial results of - these partnerships seemed to be promotional' (2003: 65).

Structural convergence occurs when media companies introduce new positions and reorganise the newsroom, and it is more related to newsgathering than management. One good example is the Orlando Sentinel's employment of multi-media editors to re-package print material for cable television. Keith Wheeler is the paper's associate managing editor for broadcast and online. Asked to describe his job, he said: 'If I have to define it, it is to get as much Orlando Sentinel content to our media partners' (2004). Information-gathering convergence also occurs at the journalistic level and is Gordon's shorthand for situations where media companies require reporters to be multi-skilled (2004: 69). It is helpful here to take a look at the most controversial form; what some people have nicknamed the 'Inspector Gadget' or 'platypus' approach (see Dailey and others 2003). Readers will recognise the platypus as the Australian mammal with the body and broad tail of a possum, and the bill and webbed feet of a duck. The term has become a disparaging description for the reporter required to do all forms of journalism. This notion of a multi-skilled journalist who can produce for all forms of media is a wonderful ideal, but in reality may not become a common occurrence. It is not possible for one person to cover a major story adequately for all media - though it is possible for this platypus or Inspector Gadget kind of reporter to handle isolated news events, or features, provided they have been trained to use all of the equipment needed. John Beeston, news director for CNN Hong Kong, tells of how he sent a reporter to Kalimantan in the Indonesian jungle with a small digital video camera, mobile phone and laptop:

She covered the story by telephone for CNN's international programs broadcast from Atlanta. In addition she reported into our regional programs that emanate from Hong Kong. She also wrote news stories 
and filed pictures for the web. When she returned to Hong Kong she brought back some sensational material, which we produced into enduring features.

Beeston said the small, lightweight equipment enabled the reporter to move around more easily than a crew of three people with numerous metal boxes. His company was able to get elements of a story that would have been impossible for a traditional TV news crew. Beeston observes that 'This approach is not always suitable, but it gives us more flexibility' (Beeston, 2001).

Gordon's final category is storytelling convergence. It operates solely at the level of the working journalist, though management support is needed for equipment. Every new medium offers innovative ways to tell stories. But these conventions take time to evolve. It is reasonable to expect that new forms of storytelling will emerge for the three new digital presentation platforms: desktop computers, portable devices and interactive television (2003: 70). Journalists are still working out how to 'do' convergence. One of the participants at the defining convergence panel in Columbia South Carolina in November 2002 pointed out that convergence was still evolving and that for him it was still an experiment: "If anyone is doing the work and considers it anything but R\&D, they are way off' (Romaner, 2002). Two years on, that situation has not changed.

For this author, full convergence is not about co-operation (sharing of resources) or partnerships or cross promotion or content sharing - the main forms operating in the United States. Full media convergence involves a radical change in approach and mindset by both managers and journalists. It involves a shared desk where the key people, the multi-media editors, assess each news event on its merits and assign the most appropriate staff for the story. Sometimes it will be an individual (perhaps an Inspector Gadget kind of journalist) but most of the time teams of people will be assigned. The size of the team will depend on the story. The multi-media editor will make each judgment based on the most appropriate medium for telling the story. A major fire may need a team of still photographers, video-journalists, online specialists and reporters. A routine press conference may only need one reporter.

Communication is a key factor. If a story evolves to the point where one person is not enough, the reporter needs to know when to call for help, and sufficiently confident to know that the call for help will not cause ridicule. 
People on the multi-media desk also need to be trained to assess a story and send the most appropriate individual or team. All information (image and text) must be fed into a central database from which relevant materials can be extracted to tell the story in the most appropriate way. Unused material must be archived to establish a knowledge base for future projects. All budgets need to be linked so that editorial managers in each medium know what the other media are doing and covering. Those editorial managers need to know enough about the strengths of other media to be able to discuss potential multi-media facets of stories. All of this calls for a change of mindset and attitude. The team is more important than the lone wolf reporter because teams produce better multi-media reporting. It also means that news organisations will need to invest in widespread training, to teach journalists skilled in one medium how to tell stories in another. In this sense convergence is not a cheap option; it will mean that media organisations will have to surrender the huge profits of the past decade in pursuit of the holy grail of journalism - quality reporting.

\section{Competing models: The business ideal}

The business model sees multiple-platform publishing as a way to increase productivity among staff while grabbing as large a share of the advertising pie as possible. Cross promotion of other media outlets in the same group is a key way to market other members of the group cheaply, and it also presents major opportunities for multiple-media advertising campaigns. One advertising representative can sell a campaign in a variety of formats. This introduces the concept of 'co-opertition'. This term is an amalgam of competition and cooperation and represents a new form of business in which organisations that originally were competitors work together when it suits each party.

Walter Keichel, editor of the Harvard Business Review, said the essence of the theory could be reduced to two sentences: 'Co-operate with others to increase the size of the pie. Compete in cutting it up.' But he inserted a cautionary note: 'The others with whom you may wish to co-operate could include businesses with which you compete on other fronts' (Keichel, 2001). John Haile, former editor of the Orlando Sentinel, and now a partner with the Haile-Gentry consultancy that advises companies on how to manage convergence, believes it is vital to protect a company's revenues. In his view convergence offers one effective way to do so. 
I was on an ASNE [American Society of Newspaper Editors] new media panel in Dallas [in 1995], and I remember answering the question of 'why do this?' with two words: 'classified advertising'. That is our largest single source of advertising, and it is the most vulnerable to interactive, searchable media. If ad[vertising] dollars start dropping, you can bet newsroom budgets will follow. That will dramatically affect our ability to do good journalism" (quoted in Gentry, 1999: 6).

Paul Horrocks, editor of the Manchester Evening News, part of the Guardian Media Group in the United Kingdom, was blunter: 'Convergence is about survival' (2002). He believes multiple-platform publishing offers many advantages in the crowded advertising and media markets of the United Kingdom:

It is [about] delivering a product that we know the customers will want. We started out on the multi-platform road 18 months ago. It is still rocky. You need a top-down commitment. Journalists, by their nature, don't like change. We have to convince them that we have to serve the customer to retain our jobs (2002).

\section{Competing models: The journalistic ideal}

Andrew Nachison of the API's Media Center believes that if journalistic values prevail in the move to multiple-platform journalism, quality will improve. He comments that 'The danger seems to lie in making news values subordinate to business considerations' (2002). Gil Thelen, publisher of the Tampa Tribune and one of the pioneers of convergence, believes multipleplatform delivery should be designed 'to help people live [their lives] more easily' (2002a). He points out that

We want to make sure these on-the-run readers can scan the paper quickly and get a good sense of what's important that day. Yet at the same time, we want to make sure that when these busy readers do catch their breath and find time to read the paper more completely, they'll enjoy the context, depth and perspective on the news that only newspapers can provide (2002b).

This remains the defining paradox of the modern newspaper - how can it present content that consumers can scan quickly, without sacrificing the 
informational quality of that content? Quality of content, generated by quality staff, will be what differentiates great news organizations from the mediocre in the future. One sure way to generate quality is to provide extensive training (Quinn, 2002b: 99).

According to Kerry Northrup, executive director of Ifra's advanced news operations, convergence does not save money. It was, however, a necessary evolution because it addressed the needs of changing audiences: 'Convergence offers ... new ways of absorbing news rather than just offering journalists new ways of presenting it. Convergence is a growth strategy instead of a saving strategy.' Northrup regarded assignment editors as the key people in convergence journalism. These people allocate tasks to reporters. In New Zealand newspapers they are called chief reporters; on Australian newspapers, news editors; at US newspapers, city editors. American television stations use the term assignment editor. Whatever the title, those editors need a mindset freed from any one medium. As Northrup points out: 'A true multiple-media editor will be one who recognises, for instance, that breaking news reporting is no longer a staple of printed journalism, and therefore that printed newspaper content must rise to a higher level while working in concert with its online siblings' (Northrup, 2000: 33). Journalists in the 21st century would need a flexible mindset and the ability to adjust to change. Brian Veseling, deputy editor of the industry newspaper Newspaper Techniques, concluded that: 'If there is one word to describe what is being required more and more in newsrooms as journalism moves into the digital age it is flexibility. In an industry in which flexibility always has been an important element for success, it now seems to be vital for survival' (Veseling, 2000: 20). Convergence, then, is about both survival and change.

\section{Convergence: Drivers and barriers}

It is useful here to consider the factors driving convergence. The main one is the changing attitudes and lifestyles of consumers. As the Tampa Tribune's Thelen has pointed out, people's information-seeking behaviours are changing and media organisations must respond to that need. A research report by BIGresearch of Columbus, Ohio found that half of consumers surveyed used multiple media simultaneously. The study found women were more likely than men to consume multiple media channels simultaneously: two in three women reported regularly watching television when they go online, as did three in five 
men (Morrissey, 2002). Ruth de Aquino, Ifra's most recent director of editorial strategy and now a newspaper editor in Brazil, has observed dramatic changes in the consumption of news since the early 1990s:

News information is all around: on mobile phones, newspapers, portable data assistants such as Palm Pilots, television, interactive and cable $\mathrm{TV}$, the internet, teletext, kiosks [units which display the news in public places], radio, video screens in hotel elevators, video programming for airlines and much more. The concept of news is changing all the time. [It is becoming] more personalized, more service-oriented and less institutional (2002: 3).

Market fragmentation is another major factor. The growth of the World Wide Web has, simultaneously, introduced another forum for advertising, while generating more niche markets. These developments have also increased the perception of a more fragmented market. Media managers want to identify and control as many sections of the audience as possible. The capacity to do so may ultimately decide whether a news organisation survives. As some of the examples later in this paper show, convergence makes it possible to reach many more audience members. However, the advertising pie - the total amount of money available to media organisations - has not changed much. Recessions in some parts of the world have meant that media companies are competing directly for audiences, and indirectly for a share of the pie.

Several factors have been identified that inhibit or slow the convergence process. They are listed here in no specific order of importance. In some countries, legislation that forbids cross-ownership - that stops a company from owning a daily newspaper and a television channel in the same city - has understandably limited or slowed the convergence process. Union concerns for their members' future is another factor. In Canada, the Newspaper Guild is concerned about convergence 'diluting' journalists' work. According to director Arnold Amber, asking a reporter to do two jobs lessens the quality of work. 'You're depleting journalism when you split up that person's focus' (Healy, 2002: 67). Companies with strong mono-media traditions such as in the UK or France tend to focus on their traditional strength. George Brock, managing editor of The Times in the UK, noted that the quality of television and radio in his country was so high that it would be foolish for a newspaper to try to emulate it. The costs would also be prohibitive, he said, so it was better 
to focus on the paper's single-media strengths, which were in-depth coverage and explanation. De Aquino has said that one of the biggest issues with convergence is the lack of adequate business models. She noted that it was difficult to plan and execute any form of multiple-platform publishing when no maps or guidelines on how to do so were available (de Aquino, 2002: 8).

Professor James Gentry, dean of the William Allen White School of Journalism and Mass Communications at the University of Kansas, has proposed a continuum between 'easy' and 'difficult' introductions of convergence. Factors helping 'easy' convergence included a focused leadership, a single owner, a flexible culture, co-location of media outlets, previous relationships between potential partners and no unions. 'Difficult' convergence arises when the organisation has different owners, other leadership priorities, multiple managers, inflexible or dissimilar cultures, disparate locations and the presence of unions. Suspicion of partner organisations based on conflicting values can also be an issue (Gentry, 2004). The availability of appropriate technology, declining economic conditions, a flexible mindset among managers and staff, and the presence of competition in the market also contribute (Quinn, 2002a: 62).

\section{Evolution of convergence around the world}

Martha Stone, senior consultant for the Innovation International media consulting group, believes that the benefits of turning media companies into multimedia organisations are 'overwhelming'. On each continent, in nearly every country, mono-media companies were 'transforming into multi-media companies, integrating editorial side operations from print, web and broadcast divisions' (2002: 1). Stone noted that 73 per cent of members of the World Association of Newspapers (WAN) had observed some form of convergence at their companies. In a separate study for WAN, Dr Juan Antonio Giner, founder of Innovation International, found that seven out of 10 newspaper executives employed reporters who had formal duties in at least one other outside medium apart from the newspaper (2001: 28). It would be safe to say that convergence is more advanced outside the United States than inside.

Media companies have embraced convergence in most areas of the world. In South East Asia, they include Utusan in Kuala Lumpur, the Malaysian capital; the Nation group in Thailand; JoongAng Ilbo and the Maeil Business Group in South Korea; the Singapore Press Holdings group, which publishes 
the Straits Times newspaper; and the Ming Pao Group in Hong Kong. In the United States, the leaders are the Tampa Tribune, the Orlando Sentinel, the Sarasota Herald-Tribune, The Washington Post and the Chicago Tribune. The Washington Post has links with the Jim Lehrer's Newshour programme on PBS, the local NBC affiliate in Washington WRC-TV and MSNBC. The Boston Globe partners with cable channel New England Cable News in Boston and a group of local radio stations. The Arizona Republic has got together with KPNX-TV in the state of Arizona. USA Today is sharing material with 21 local television stations in the Gannett group, the biggest media chain in the country. The Bell Globe Media group in Canada owns the national daily The Globe and Mail and a television news service, The Business Report. Professor Gentry provides a convergence tracker on the web site of the American Press Institute that shows convergence occurring in 31 states. (see www.americanpressinstitute.org/convergencetracker). Howard Finberg of the Poynter Institute said that at least 100 of the 1457 daily newspapers in the US had embraced convergence in a big way (2004).

In Europe, the Bertelsmann group has pioneered convergence in Germany, as have the Financial Times and the BBC in the United Kingdom. In Spain, the Marca group captures 62 per cent of the daily sports market through a combination of the daily newspaper (which has a sports focus and a circulation of 564,000) and a huge web site that offers plenty of multi-media content. The Scandinavian nations are particularly advanced. Aftonbladet and the Bonnier group are pioneers in Sweden, as is Norway's Aftenposten. Schibsted ASA and Sweden's national labour organisation own Aftonbladet. The Turun Sanomat Group in south-west Finland is one of the world's leaders in multiple-platform publishing. Editor-in-chief Ari Valjakka estimates that his group reaches 40 per cent of his audience twice in any given day (Valjakka, 2002b).

$\mathrm{CNN}$ declares that it is a world leader in the area of convergence. Chris Cramer, head of news, said his journalists were required to work on a daily and hourly basis, providing content for television, radio and online services. He told the Media Report programme on the Australia Broadcasting Corporation:

\footnotetext{
We're not talking about deskilling, we're talking about multi-skilling, or double or treble-skilling. A cameraman at $\mathrm{CNN}$ is a journalist, an editor at $\mathrm{CNN}$ is a journalist. A journalist is a journalist, and they're all producing content for a variety of different $\mathrm{CNN}$ services. Other people kind of talk the talk, but we really do walk the walk at CNN (2002).
} 


\section{Key factors related to convergence}

It is worthwhile studying those factors common to the most successful converged media operations. The first is a top-down management approach that is, convergence must be imposed from above and have management buyin. At the Orland Sentinel in Florida, for example, new recruits join the paper on the understanding that they will operate as multi-skilled reporters. Another common factor is the placing of people with different skills in the same physical space to generate trust and sharing of ideas. At the Ming Pao daily in Hong Kong, chief editor Paul Cheung said that parent company Ming Pao Enterprise Corporation hired five senior journalists or photographers from TVB, Hong Kong's biggest television news station, to help with the move to multiple-journalism (Cheung, 2001). News organisations need a way to flow information and content through the organisation in such a way as to make content available for multiple platforms. Forrest Carr, news director for WFLA-TV in Tampa in Florida, which partners with the Tampa Tribune to provide converged news, said all the newsrooms shared story ideas via a custom-built software called Budget Builder. Technologies such as a common database and intranets permit the easy distribution of information (Carr, 2002).

These technologies are vital because data and information are the lifeblood of the modern media organisation. Rolf Lie, editor of Norway's Aftenposten, believes the future is not about paper or electronics. 'It's about information. Today's journalist should say: "I'm not working in a newspaper, I'm working in news" (2000). This involves a change of mindset, which is another feature of news organisations that have successfully embraced convergence.

Harald Ritter, Ifra's research chief, said the major challenge facing publishing companies was how to make best use of new technology systems. This necessitated, he said, altered structures and new workflow and decisionmaking structures. But not all newspapers were prepared to commit themselves to taking this difficult path: "A particular stumbling block is the "inner censor" in the heads of many managers and employees, which can decrease the effectiveness of a content management system' (2001:35). The chief editor of the Ming Pao daily in Hong Kong, Paul Cheung, said the move to a multi-media environment could only be successful if accompanied by a corresponding change in the attitude of journalists. But the transformation must occur first in the minds of editorial managers: 'From my point of view, the chief editor has 
an important role. He must be the leader in terms of change' (2001). Ulrik Haagerup, until recently editor of the Jyllands-Posten in Denmark, looked at the situation from a different perspective but came to the same conclusion:

It is only in English that 'newspaper' has something to do with paper. Media convergence has nothing to do with technology or architecture. It has everything to do with mindset. Think differently-the Apple credo. People out there are moving fast. They are changing the way they use their news media and we have to change with them' (2002).

Another key factor is the need to invest in training and education. Editorial managers must realize that technology is merely a tool for doing better journalism, and journalists need training to use these tools effectively. Encouragement must come from the top. Editorial managers must be willing to foster an environment that facilitates learning. One of the key roles of journalism in the forthcoming knowledge age will be to turn information into knowledge to synthesise it for their audiences. This takes training, which requires an investment of time and money. Respected MIT economist Lester Thurow has condemned employers in the United States for their attitude to training: 'The basic problem in the United States is that every employer wants to free-ride the training system.' Whenever the jobless level improves, he said, companies complain about the shortage of skilled workers - yet these complaints come from the same companies that do not train. 'They know that they need a better trained workforce but think that someone else should take the responsibility for, and bear the cost of, creating it' (1999: 269). Media companies need to invest in training. In 2002 a national survey published by the American Society of Newspaper Editors showed that journalists were desperate for training:

Lack of training is journalists' biggest source of job dissatisfaction, even ahead of pay and benefits. More than two thirds of journalists receive no regular training. Overall, news companies have not increased their training budgets since [publication of] the 'No train, no gain' report in 1993. News executives acknowledge they should provide more training, but blame money and lack of time for their failure to do so (Newton 2003: 9). 


\section{Democracy and convergence}

It is important to recognise that media are more than just a business - the profession of journalism also has a public responsibility. Some people worry that the 'gather once, publish many times' process of convergence will produce a single message. This in turn could inhibit the variety of voices that democracy needs. Joel Carr, administrative vice-president of the Communications, Energy and Paperworkers' Union of Canada, has called for clear distinctions between different newsrooms: 'When all the feed [news and information] goes through one pipe and out to two platforms, it is scary for democracy and civil society because its very blood - discourse and free access to information - is diluted' (quoted in Healy 2002: 65). Professor Guy Berger, who runs South Africa's most distinguished journalism school at Rhodes University, is similarly concerned about the 'centralisation' produced by multi-platform publishing. In his view: 'It makes for fewer voices reporting on each story, and there is a diminution of diversity.' Perhaps it comes down to a trade-off, he suggests:

If convergence through multi-skilling helps sustain endangered media enterprises, this contributes to broader media pluralism. That can compensate for any narrowing of perspective or homogenising of content that might result from converging the news process. And if journalists are versatile and broad-minded, they can do a lot to promote diversity in coverage within and across all platforms (2001: 96).

Technological change has made the media more significant in people's lives. A quarter of a century ago, media companies played a relatively unimportant role in the economy compared with the then dominant players in manufacturing, mining, oil and automobile production. The rise of media giants has illustrated the power of information and knowledge as commodities. American academic Dr Robert McChesney has predicted that five to eight huge monoliths will dominate the US market, and 50 to 80 companies will control the world information market. Eight world giants - Time Warner, News Corporation, Disney, Viacom, General Electric, Vivendi-Universal, Sony Corporation and Bertelsmann generate more revenue than the GDP of all South Pacific countries. Despite a huge increase in the volume of media available to consumers, we are witnessing a shrinking of the number of companies that control that content. 
Yet ironically, despite the concentration of ownership - and the associated dangers for democracy - media consumers face significantly more choice. Media commentator Chris Schumway has said that many executives and media consultants believe that well-managed convergence would boost profit margins and improve journalism along the way. He concluded that a tightly run, multi-media news factory could do the former. But the latter was not likely, he said: 'Convergence journalism values speed, quantity and content adaptability above all else. Reporters accustomed to working in only one medium are likely to find themselves under constant pressure to churn out stories. Reporters working under these conditions will spend less time doing critical research and conducting interviews with diverse sources.' Speed increased the likelihood of factual errors. Schumway warned that this would result in media reports dominated by official sources such as press releases or corporate public relations material. Rather than generating diverse and wellresearched content for distinct media, he said, convergence was likely to produce more sensational types of stories or an increase in the 'commercial fluff' that dominated television and newspapers in the United States. He also noted another potential problem: 'All this cross-ownership, consolidation and convergence will have another drawback less visible to the public: the reduction of serious media criticism.' Newspaper reporters working for a converged company that owned or partnered TV stations would be discouraged from criticising their media partners or investigating institutional corruption. Likewise, reporters and other workers could be fired if they exposed ethical conflicts or openly criticise the anti-democratic concentration of media power. Schumway states that 'In effect, the ability of the media to police itself through internal criticism - which is already tenuous - will deteriorate further' (Schumway, 2002).

\section{Conclusion}

Convergence produces many challenges for publishers and journalists. Both groups need to gather and produce news for different platforms without compromising the unique qualities of each platform and the needs of their audiences. They also need to recognise the tension between their inter-linked aims - a combination of telling the truth and making money. But ultimately both journalists and publishers need to realise that journalism is not about platforms or finding content to fill each platform. The role of journalism is to 
tell stories with a purpose - to help citizens make choices in an increasingly complex world. Or, as Kovach and Rosenstiel put it so elegantly in their excellent book The Elements of Journalism, journalism needs to be a product of 'sense-making based on synthesis, verification and fierce independence' (2001: 197). If managers introduce convergence simply as a way to save money, reporters could become too busy to verify the information they find, and resort to publishing material supplied by professional spin-doctors. Journalists could get so busy providing content for multiple platforms that they simply do not have the time to reflect or analyse. Various manifestations of this problem will provide media professionals and academics with material for years to come.

\section{Note}

1 Ifra's name originates from 'INCA-FIEJ Research Association', whereby 'INCA' stands for 'International Newspaper Colour Association' and 'FIEJ' stands for 'Fédération Internationale des Editeurs de Journaux. Ifra is based with headquarters in Darmstadt (near Frankfurt), Germany.

\section{References}

Aeria, M. (2002). Comment made November 13 during the defining convergence roundtable at the third international Ifra summit, Defining Convergence, held in conjunction with the University of South Carolina, November 13-14.

Beeston, J. (2001). CNN Hong Kong: The digital news room. Presentation to the World Association of Newspapers in Hong Kong, June 5.

Berger, G. (2001). Configuring Convergence. Grahamstown: New Media Lab.

Carr, F. (2002). Personal communication, Bangkok, Thailand. March 20.

Cheung, P. (2001). Personal communication, Hong Kong, June 7. Also quoted in Loh, newspaper techniques, December 2000, pp 46-48.

Cramer, C. (2002). Media Education and the Future of TV News. Broadcast on Media Report, Australian Broadcasting Corporation, February 28.

www.abc.net.au/rn/talks/8.30/mediarpt/stories/s492884.htm

Dailey, L.; Demo, L. and Spillman, M. (2003). The convergence continuum: A model for studying collaboration between media newsrooms. A paper submitted to the Newspaper Division of the Association for Education in Journalism and Mass Communication, Kansas City, Missouri, August.

de Aquino, R. (2002). The print European landscape in the context of multimedia. Presentation to Mudia (Multimedia in a Digital Age) in Bruges, Belgium, May. www.mudia.org

Gentry, J. (2004). Presentation to journalism educators at the Poynter Institute, St Petersburg, February 9. 
Giner, J. A. (2001). From media companies to 'information engines'. In Innovations in Newspapers 2001 World Report, Innovation International, Pamplona, Spain, pp 28-33. See also www.innovacion.com

Gordon, R. (2003). The meanings and implications of convergence. In K. Kawamoto(ed.). Digital Journalism: Emerging Media and the Changing Horizons of Journalism (pp 57-73) . Rowman \& Littlefield Publishers.

Healy, T. (2002). Jack of all trades, master of none. In Ryerson Review of Journalism, Summer 2002, pp 65-7.

Haagerup, U. (2002). Presentation made November 13 during the defining convergence roundtable at the third international Ifra summit, Defining Convergence, November 13-14.

Horrocks, P. (2002). Comment made November 13 during the defining convergence roundtable at the third international Ifra summit, Defining Convergence, held in conjunction with the University of South Carolina, November 13-14.

Keichel, W. (2001). Co-opetition true and false: An alternative to convergence? Presentation to the World Association of Newspapers in Hong Kong, June 6.

Kovach, W. and Rosenstiel, T. (2001). The Elements of Journalism. New York: Three Rivers Press.

McChesney, R. (1999). Rich media, poor democracy: communication politics in dubious times. Urbana: University of Illinois Press.

Morrissey, B. (2002). Simultaneous media use poses ad challenge. In the Internet Advertising Report. www.internetnews.com/IAR/article.php/1547271

Nachison, A. (2002). Comment made November 13 during the defining convergence roundtable at the third international Ifra summit, Defining Convergence, November 13-14.

Nachison, A. (2004). Telephone interview, February 17.

Nadeau, R. and Giasson, T. (2003). Canada's democratic malaise: Are the media to blame? In Choices, 9 (1), February.

Newton, E. (2003). Great demand, weak supply. In the Learning Newsroom, published by the American Society of Newspaper Editors, 9 .

Northrup, K. (2000). New skills needed for today's 'multiple media' stories. In PANPA Bulletin, Pacific Area Newspaper Publishers' Association, November pp 32-3.

Northrup, K. (2002). Opening presentation to the third international Ifra summit, Defining Convergence, held in conjunction with the University of South Carolina, November 13.

Pavlik, J. (2002). New Media and Journalism Education: Preparing the Next Generation. In Journalism and New Media. New York: Columbia University Press, 2002, pp193-208.

Pfeiffer, A. (2000). Emerging opportunities in the expanding media space. www.ifra.com/NewsFeed.nsf.

Pryor, L. (2004). Email interview, August 2.

Quinn, S. (2001). Convergence journalism in the United States and Asia, and the implications for journalism, collected in the proceedings of the Australian Broad- 
casting Authority's conference on Radio, Television and the New Media, Canberra, May 3-4, pp 204-24.

Quinn, S. (2002a). Knowledge Management in the Digital Newsroom. Oxford: Focal Press.

Quinn, S. (2002b). Media convergence: Implications for journalism education. In Australian Studies in Journalism, Number 10/11, December, pp 85-105.

Romaner, M. (2002). Comment made November 13 during the defining convergence roundtable at the third international Ifra summit, Defining Convergence, November 13-14.

Ritter, H. (2001). Work in all media, manage content and publish digitally. In Newspaper Techniques, December, pp 34-5.

Schumway, C. (2002). Big media about to get even bigger. In Mainstream Media Watch,January 21.www.zmag.org/content/MainstreamMedia/shumway_media.cfm

Stone, M. (2002). Multimedia integration is here to stay. In Online Newspapers and Multimedia Newsrooms, Number 4, April.

Thelen, G. (2002a). Comment made November 13 during the defining convergence roundtable at the third international Ifra summit, Defining Convergence, November 13-14.

Thelen, G. (2002b). A renewed Tribune to serve you better. On Tampa Tribune online. promos.tampatrib.com/promos/readersguide/gil.htm

Thurow, L. (1999). Building Wealth: The new rules for individuals, companies and nations in a knowledge-based economy. New York: HarperCollins.

Tyner, H. (2000). Speaking during a presentation at the Newsroom for a Digital Age seminar in Darmstad, Germany in October.

Tyner, H. (2002). Comment made November 13 during the defining convergence roundtable at the third international Ifra summit, Defining Convergence, 13-14 November 13-14.

Valjakka, A. (2002a). November 13. Presentation 'Convergence by the numbers' at the third international Ifra summit, Defining Convergence, November 13-14.

Valjakka, A. (2002b). Personal communication, Dubai, December 30.

Veseling, B. (2000). Flexibility the key in the multi-media world. In PANPA Bulletin, November 2000, pp 20-23.

Wheeler, K. (2004). Personal communication, St Petersburg, February 10.

Dr Stephen Quinn is an associate professor in the Department of Journalism at Ball State University in the United States. He taught journalism in New Zealand (1990-95), Australia (1996-2001) and the United Arab Emirates (2001-03).

squinn@bsu.edu 